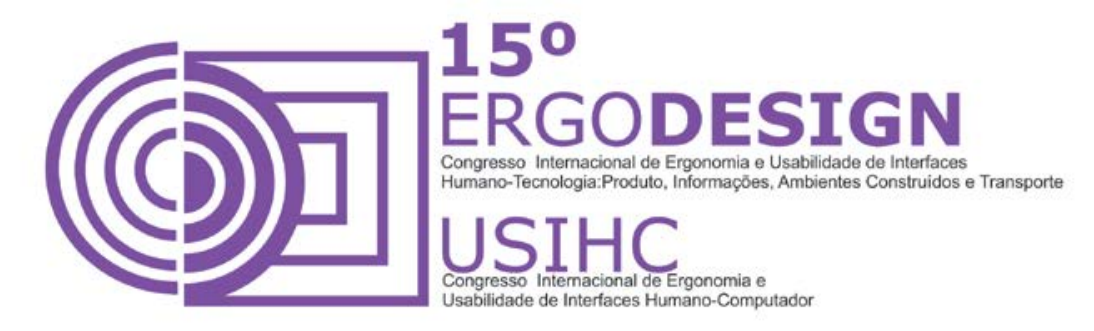

\title{
AVALIAÇÃO DA USABILIDADE DE ÍCONES DE APLICATIVO DE DISPOSITIVO MÓVEL UTILIZADO COMO APOIO EDUCACIONAL PARA CRIANÇAS NA IDADE PRÉ-ESCOLAR
}

\author{
EVALUATION DEVICE APPLICATION ICONS USABILITY MOBILE \\ USED AS EDUCATIONAL SUPPORT FOR CHILDREN IN PRESCHOOL \\ AGE
}

\author{
SANTOS, Fernanda Mendes de Vuono (1); \\ FREITAS, Sydney Fernandes de (2);
}

(1) Universidade do Estado do Rio de Janeiro, Mestranda em Design

e-mail:fvuono@esdi.uerj.br

(2) Universidade do Estado do Rio de Janeiro, DSc em Engenharia de Produção

e-mail:sydneyfreitas@terra.com.br

\begin{abstract}
RESUMO
Ícones utilizados em aplicativos de jogos educativos infantis para dispositivos móveis apresentam sérios problemas de usabilidade que induzem as crianças a erros e levam à desmotivação. Este artigo apresenta os resultados de um estudo dos ícones utilizados na construção da interface do aplicativo de um livro de jogos educativos para crianças na faixa de três a cinco anos, seu reconhecimento na idade pré-escolar e consequente eficácia no auxílio da educação. Após a definição da amostra e a seleção da atividade aplicou-se a técnica avaliação cooperativa. Conclui-se com a apresentação de diretrizes para atividade projetual de ícones para crianças.
\end{abstract}

Palavras-chave: Ergonomia, Dispositivo Móvel, Educação Infantil, Usabilidade, Ícones.

\begin{abstract}
Educational game icons used in mobile devices applications for children have significant usability problems that may induce to errors and demotivation. This article addresses the results of a study of a mobile application interface icons used in a book of educational games for children between the ages of three and five years old in regards to its value and effectiveness as an education aid to a preschooler's curriculum. A cooperative evaluation technique was applied over the data sample and the selection of activities. We conclude with the recommendation and guidelines for project design for icons for children.
\end{abstract}

Keywords: Ergonomics, Mobile Device, Child Education, Usability, Icons. 


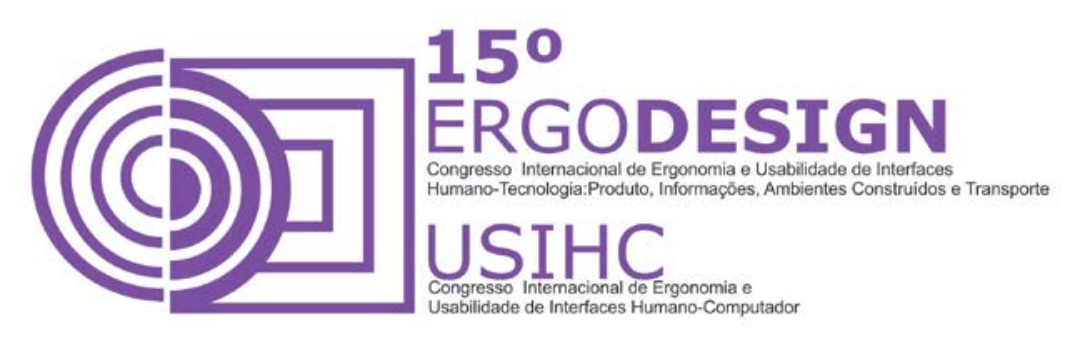

\section{INTRODUÇÃO}

Com a franca expansão tecnológica, surge a necessidade de integração de novas tecnologias às atividades de sala de aula. As atividades infantis transcendem o universo de livros e cadernos. O processo de aprendizado está na dependência de que escolas e docentes estejam atentos às novas demandas e aos desejos do aluno bem como a atualização do conhecimento tecnológico.

Embora alguns educadores ainda se sintam despreparados e até mesmo letárgicos em face à esse crescente avanço tecnológico, muitos já perceberam seu potencial e sua importância como facilitador no processo do ensino. Percebe-se que a tecnologia é uma grande aliada à educação, uma poderosa ferramenta que amplia e leva o processo de ensinar à um patamar diferenciado do ensino tradicional.

Muitas escolas já incorporaram a tecnologia ao seu método de ensino. Essa sintonia entre aluno e tecnologia é fundamental para prepará-los para ingressar no mundo digital atual. 0 uso da tecnologia em sala de aula aproxima o professor do universo do aluno, fazendo com que este passe de mero espectador a participante, através de uma aula mais interativa. A ideia não é abandonar o quadro negro e sim agregar novas possibilidades ao atual cenário do ensino.

Vivemos na era do digital. Do reflexo das telas na face de nossos filhos, diariamente imersos no mar infinito da web. Da conexão constante em casa pelo modem, nas ruas por meio dos celulares e em cafés com redes sem fio (wireless). Nos últimos anos, o domínio da internet chegou a um dos locais mais protegidos pela sociedade: a escola. (SHINYASHIKI, 2009)

Os dispositivos móveis, como os tablets, são de grande contribuição nesse processo e vêm ganhando cada vez mais espaço nas escolas. A possibilidade de maior interação, o fácil manuseio, a conectividade simples e rápida e a interface amigável faz com que a preferência por esses dispositivos seja maior até mesmo do que os computadores tradicionais utilizados nas aulas de multimídia. Em face a esse panorama, a disseminação de aplicativos educacionais em diversas áreas do ensino vem crescendo rapidamente, tornando necessário um estudo mais criterioso de suas interfaces e adequações ao universo infantil.

Segundo a Lei de Diretrizes e Bases da Educação Nacional, nº 9.394 /1996, a educação escolar é formada por Educação Básica, constituída pela Educação Infantil e onde está inserida a pré-escola, que abrange crianças de quatro a seis anos de idade, Ensino Fundamental, Ensino Médio e Ensino Superior. A Educação Básica tem por finalidade desenvolver o educando, assegurar-lhe a formação comum indispensável para o exercício da cidadania e fornecer-lhe meios para progredir no trabalho e estudos posteriores. É nessa fase que acontece o desenvolvimento integral da criança em seus aspectos físico, psicológico, intelectual e social e considerada por muitos educadores como a fase mais importante para o desenvolvimento cognitivo do indivíduo.

"É evidenciada a importância da fase pré-escolar, tanto no que diz respeito ao processo de maturação biológica como ao desenvolvimento sócio-psicomotor por que passa a criança em seu relacionamento com o meio ambiente". (GANDRA, 1981) 


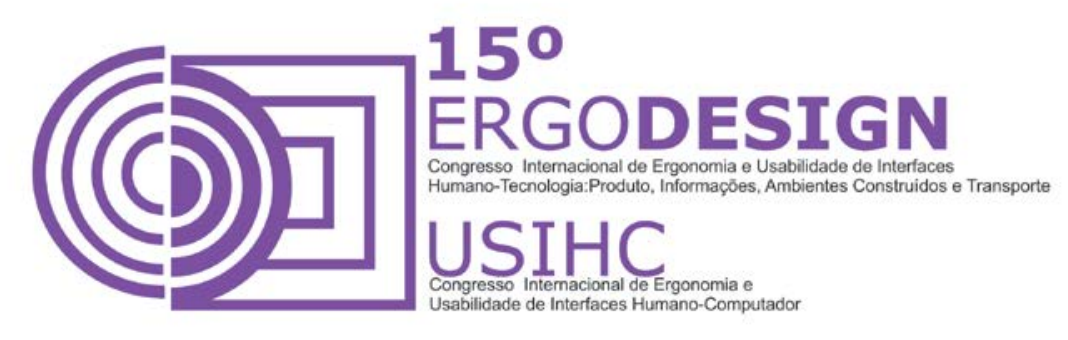

\section{DISPOSITIVOS MÓVEIS E USABILIDADE}

Segundo LEE (2005), mobilidade é a capacidade de poder se deslocar ou ser deslocado facilmente; no contexto da computação móvel, são dispositivos funcionalmente poderosos, oferecendo a capacidade de realizar facilmente um conjunto de funções, aplicações, sendo também capazes de conectar-se, obtendo e fornecendo dados. Nesta categoria podemos incluir os smartphones e tablets, estes últimos muito utilizados como suporte ao aprendizado.

Os dispositivos móveis, por meio de suas possibilidades interativas, traduzidas por fatores como mobilidade, telas sensíveis ao toque e aplicativos de temas variados, provocam uma exploração intuitiva. Vêm se disseminando nas escolas, principalmente a partir de 2010, com o lançamento e popularização do iPad, tablet desenvolvido pela Apple. Sua inserção no ambiente escolar traz desafios em um universo ainda pouco explorado. Eles permitem e facilitam a comunicação, favorecem a colaboração, em qualquer lugar já que ampliam o acesso às informações. Além disso, exige o uso de uma nova linguagem, tanto por parte das escolas, como dos professores, que devem dominar não somente as questões técnicas e de usabilidade, mas contribuir com a reflexão de como os tablets estão sendo incorporados no dia-a-dia escolar.

O FNDE, Fundo Nacional de Desenvolvimento da Educação criou o Prolnfo, inicialmente denominado de Programa Nacional de Informática na Educação. Criado pelo Ministério da Educação, através da portaria no 522 em 09/04/1997, tem como objetivo promover o uso da tecnologia como ferramenta de enriquecimento pedagógico no ensino público fundamental e médio, onde desenvolveu um programa de formação voltado para o uso didático-pedagógico das tecnologias no cotidiano escolar, articulado à distribuição de tablets nas escolas e à demanda de conteúdos e recursos multimídia e digitais. Apesar de ainda não ser uma realidade para todas as escolas, podemos constatar dessa forma a percepção por parte do Ministério da Educação da necessidade de implementação de novas tecnologias em sala de aula, pois o uso de dispositivos móveis está cada vez mais inserido no cotidiano e no ambiente escolar.

"A usabilidade funciona porque revela como o mundo funciona. Depois de descobrir como as pessoas interagem com seu projeto, você pode torná-lo melhor que o do seu concorrente". (NIELSEN, 2007)

A usabilidade é um atributo de qualidade relacionado à facilidade de uso da interface. Refere-se à rapidez com que os usuários podem aprender a usar alguma interface, a sua eficiência, o quanto lembram e sentem-se satisfeitos ao utilizá-la. Para construir uma interface com boa usabilidade há a necessidade da análise dos diversos elementos de seu contexto de uso e da participação ativa do usuário nas decisões de construção da interface, incluindo a compreensão dos ícones representativos dos comandos. Para orientar o design de interface como a geração de ícones e dar suporte à avaliação de usabilidade do design de interface, existem conjuntos de heurísticas de usabilidade representando regras, como as dez heurísticas de Nielsen (NIELSEN, 1993), as oito regras de ouro de Shneiderman (SHNEIDERMAN, 1998) e os critérios ergonômicos de Bastien e Scapin (BASTIEN; SCAPIN, 1993) entre outros.

Para que os aplicativos educacionais atinjam o seu público alvo eles precisam interagir de uma forma eficiente com as crianças. A fácil compreensão da navegação e dos ícones que compõem a interface precisa ser percebida desde o início, fazendo com que a criança não perca o interesse pelo aplicativo e consequentemente prejudique o seu aprendizado. Além 


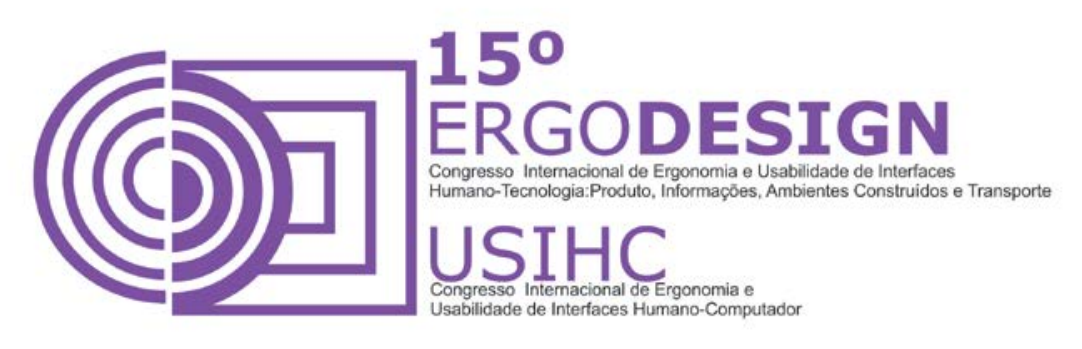

disso, essa interface precisa ser amigável, lúdica, levando a criança para um mundo de brincadeiras, onde aprender se torna uma atividade prazerosa. Muitas vezes, a interação acaba acontecendo porque a criança aprende a utilizar determinado aplicativo e memoriza o processo. Ou seja, ele não se dá de forma intuitiva, pois o desenho dos ícones apresentados está muito distante da realidade desse público e para que sejam funcionais, precisam conectar o design à usabilidade.

"A preocupação com as características do usuário, de forma abrangente, define o enfoque do design e o diferencia de outras disciplinas, inclusive da psicologia cognitiva e da ergonomia do software. Esse enfoque coloca a estética em evidência, em plena consciência de poder". (BONSIEPE, 2011)

\section{APLICATIVOS EDUCACIONAIS}

Um aplicativo, ou App, como é popularmente conhecido, é um programa desenvolvido especialmente para as plataformas móveis, como smartphones e tablets. Os aplicativos educacionais são programas desenvolvidos para auxiliar no processo de ensino dentro e fora das escolas. É uma potencial ferramenta para diferentes áreas e abrange uma extensa faixa etária.

Podemos encontrar nas lojas online como a Apple Store, uma infinidade de aplicativos, pagos e gratuitos, que são utilizados como ferramenta de apoio ao ensino nas escolas. Vão desde aplicativos para a pré-escola, como livros de colorir até aplicativos desenvolvidos para o auxílio do ensino da matemática, o que caracteriza a diversidade e o infinito leque de possibilidades de desenvolvimento de aplicativos para a área educacional.

\section{PERFIL DA POPULAÇÃO}

A tecnologia como ferramenta pedagógica coloca à disposição do aluno um universo de possibilidades. Diversos dispositivos oferecem o acesso, não apenas nos computadores pessoais, mas através de dispositivos móveis (smartphones, tablets e notebooks) que têm revolucionado a comunicação.

O avanço da tecnologia transforma cada vez mais a rotina das crianças. Brincadeiras coletivas na rua, como jogar bola e brincar de boneca concorrem lado a lado com os jogos multimídia. Essa nova realidade, desenhada em função do desenvolvimento tecnológico e do aumento da violência, carrega a brincadeira da rua para dentro de casa e possibilita a realização de diversas tarefas simultaneamente.

As crianças mostram grande interesse quando o assunto é tecnologia o que torna necessária uma análise de seu comportamento quando em contato com essa realidade. Muitas vezes a falta de interatividade, gerada pela baixa compreensão do significado dos ícones presentes nos aplicativos utilizados como apoio ao ensino, gera o desinteresse e consequentemente o aprendizado fica prejudicado.

Para uma pesquisa mais abrangente, há a necessidade de conhecer o estudo e classificação das gerações ao longo dos anos. Segundo estudos sociológicos, as gerações foram divididas a cada vinte anos: Belle Epoque (1920 a 1940); Baby Boomers (1940 a 1960); Geração X (1960 a 1980); Geração Y (1980 a 2000), Geração Z (2000 a 2010) e Geração ALFA (2010 em diante). 


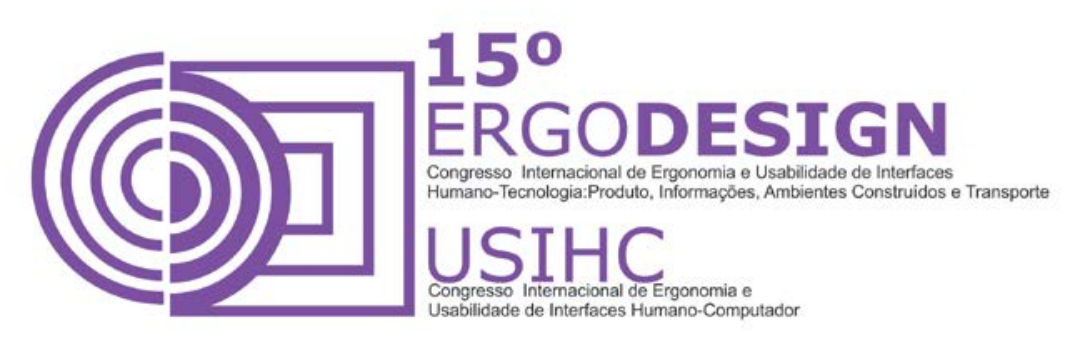

A Geração Y, é a geração que está se inserindo no mercado de trabalho e, está começando a influenciar de maneira mais direta os destinos da sociedade. Esta geração tem por características: serem multitarefas, ou seja, conseguem fazer várias coisas ao mesmo tempo; a busca pelo reconhecimento no trabalho e a necessidade de constantemente estarem recebendo feedbacks para tudo que fazem; procuram estabelecer relações de informalidade com o trabalho, onde a valorização da liberdade foi substituída por flexibilidade e conveniência, bem como tendo adotado comportamentos de individualidade, estimuladas pelas facilidades da tecnologia; e ampliação dos relacionamentos, facilitada pela tecnologia. (OLIVEIRA, 2010)

A sucessora da Geração Y é a Geração Z, formada por pessoas nascidas a partir do ano 2000 , constantemente conectadas através de dispositivos móveis e inseridas no contexto da sustentabilidade. O "Z" vem de "zapear", palavra derivada do inglês "zap", que significa fazer algo rapidamente, energia e entusiasmo. São jovens e crianças que estudam enquanto assistem à televisão e ouvem música ao mesmo tempo, ou seja, estão acostumados a realizar várias atividades simultaneamente. São inquietos, curiosos e em constante transformação. É uma geração que nasceu atrelada à tecnologia e vive como se fosse impossível dissociar a rotina da vida conectada, permanentemente online. É como se as tarefas não pudessem ser realizadas sem a internet, o computador, o tablet ou o smartphone. Estão acostumados a muita informação em pouco tempo e acabam não se dedicando plenamente a nenhuma tarefa e nem sabendo lidar com esse conteúdo que rapidamente se tornará obsoleto.

"Atualmente ocupando as classes de ensino fundamental e médio, a "geração Z" acabou com o reinado das aulas expositivas. Já não bastam intercalar conteúdos e exercícios: para atrair a atenção dos jovens, a tecnologia é a principal aliada dos professores". (CHERUBIN, 2012)

A geração atual é conhecida como "ALFA"(ou APLHA GENERATION) que corresponde a pessoas nascidas a partir de 2010 e em um mundo conectado em rede. Podem ser filhos tanto da Geração Y, como da Geração Z. O foco dessa pesquisa é a criança na fase préescolar, que abrange quatro a seis anos e que portanto está inserida tanto na Geração Z, quanto na Geração ALFA.

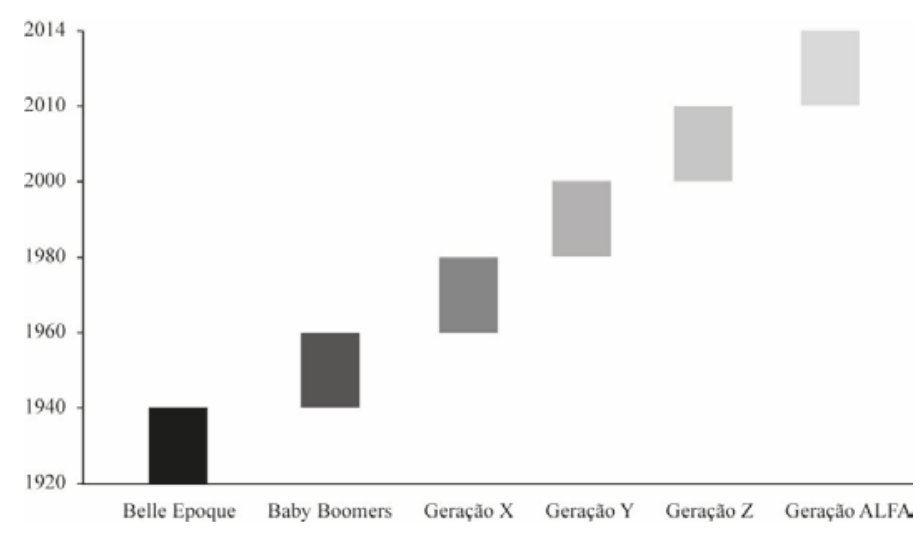

Figura 1- Gráfico da classificação das gerações. 


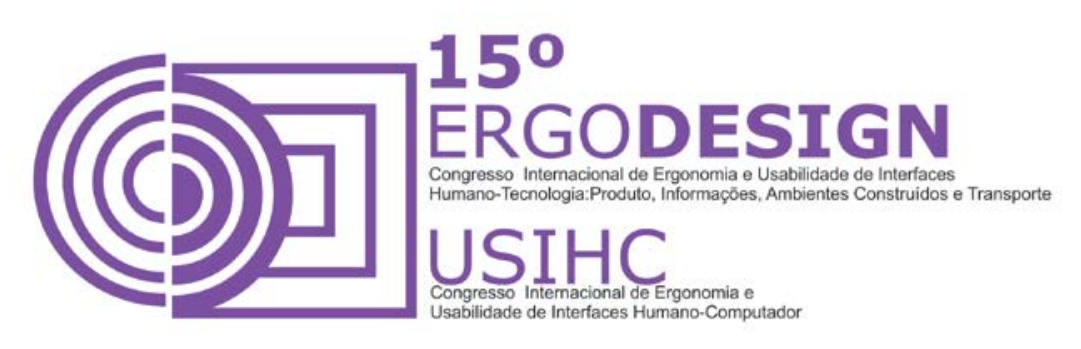

\title{
5. OBJETIVO
}

O objetivo é contribuir para o estudo e desenvolvimento de ícones que melhor representem as atividades infantis em ambientes virtuais e facilitem a utilização de forma mais intuitiva, auxiliando no processo educacional e contribuindo para pesquisa de desenvolvimento de novos ícones para implementação em aplicativos e softwares educacionais.

\section{MÉTODO DE PESQUISA}

A ergonomia é a qualidade de adaptação de um dispositivo a seu operador e à tarefa que este realiza. A usabilidade se revela quando os usuários empregam o sistema para alcançar seus objetivos em um determinado contexto de operação, sendo caracterizada pelo nível de eficácia, eficiência e satisfação alcançado pelo usuário durante seu uso. (CYBIS, BETIOL e FAUST, 2010)

Utilizou-se a avaliação cooperativa que permite obter dados sobre o aplicativo em análise, ressaltando os pontos que devem ser alterados, através de sugestões do usuário para melhoria da interface. A proposta da avaliação cooperativa, não é identificar todos os problemas na interface, mas sim levantar questões e identificar os problemas mais importantes e que devem ser corrigidos. É um método recomendado para sistemas que já estão prontos, pois é através da interatividade com a estrutura completa que o usuário poderá identificar os problemas com maior facilidade e clareza.

Este tipo de avaliação envolve ativamente o usuário e é bastante simples, não necessitando de uma vasta experiência em interação humano-computador.

\begin{abstract}
A avaliação cooperativa é mais útil para um feedback inicial sobre redesign, num ciclo interativo rápido de desenvolvimento. A intenção da avaliação cooperativa não é fornecer uma lista exaustiva de todos os problemas que possam ser identificados, mas sim ajudar a identificar, com o mínimo esforço, os problemas mais importantes. Contudo, pode ser usada como um produto existente que deve ser melhorado ou ampliado, com um protótipo parcial ou simulação ou com um protótipo completamente funcional. É importante ressaltar que se deve evitar aplicá-la nas fases embrionárias de projeto pela carência de requistos e informações sobre as tarefas a serem executadas. (SANTA ROSA e MORAES, 2012)
\end{abstract}

Para que a avaliação seja considerada cooperativa, segundo Monk (1996), ela deve estar de acordo com os seguintes procedimentos:

a) Recrutamento de usuários que irão participar da avaliação - estes usuários devem ser o mais próximo do público-alvo, do usuário do sistema, apresentando a mesma faixa etária, habilidades, temperamento, grau de conhecimento entre outros.

b) Lista de tarefas - as tarefas devem conter as principais áreas do aplicativo. A seleção correta das tarefas é primordial para a eficácia da avaliação e devem testar ao máximo o aplicativo.

c) Condução das sessões - a avaliação deve ser registrada por meio de gravações e anotações, enquanto o usuário testa o sistema, deixando claro para o usuário que quem está sendo testado é o aplicativo e não ele. Monk (1993) sugere, para facilitar o andamento da avaliação, o uso de perguntas como: 


\section{(C))}

- Como nós fazemos isso?

- O que você quer fazer?

- O que o sistema fez agora?

- Por que o sistema fez isso?

- O que você está fazendo agora?

d) O avaliador identifica e faz perguntas sobre possíveis sugestões de melhoria no sistema, após análise de suas anotações e gravações.

O avaliador deve encorajar o usuário a relatar os problemas que encontra durante o uso do sistema e sugerir melhorias, de forma colaborativa. Esta técnica foi escolhida por ser simples de ser aplicada, pois crianças pequenas nem sempre conseguem explicar o que compreendem de forma clara e objetiva, sendo a atividade participativa e melhor forma de identificar as dificuldades e facilidades de uso do aplicativo.

\section{LEVANTAMENTO DOS APLICATIVOS DISPONÍVEIS}

Ao realizar uma busca nas lojas digitais, foram encontrados diversos aplicativos na área da educação, abrangendo uma extensa faixa etária. Buscando aplicativos que atendessem à demanda da pesquisa, foi constatado que é maior o número de aplicativos disponíveis em inglês. A busca foi feita por categoria (educação e jogos educativos) e faixa etária. Também foram selecionados aplicativos que reproduzissem os livros de colorir utilizados em sala de aula, por ser uma atividade familiar à criança, que não possuíssem muitas palavras mas sim muitas imagens, com a navegação se restringindo aos ícones, que fossem gratuitos e que tivessem um número considerável de downloads realizados.

O resultado da pesquisa dos aplicativos selecionados está listado no quadro abaixo:

Tabela 1 - Tabela de aplicativos selecionados nas categorias Educação e Jogos Educativos.

\begin{tabular}{|c|c|c|c|c|}
\hline $\begin{array}{c}\text { Nome do aplicativo para } \\
\text { IPad }\end{array}$ & Categoria & Desenvolvedor & Idioma & Valor \\
\hline Crie com Click & Educação & Globosat & Português & Gratuito \\
\hline Wee kids draw \& color & Jogos & Ebooks \& Kids & Inglês & Gratuito \\
\hline Livro de colorir para crianças! & Jogos & Peep Software & Português & Gratuito \\
\hline $\begin{array}{c}\text { Jogos Educativos para } \\
\text { crianças de 4-6: saiba os } \\
\text { números de 1-20 }\end{array}$ & Jogos & Escaleto UG & Português & Gratuito \\
\hline Drawing with Carl & Educação & Tayasui & Inglês & Gratuito \\
\hline $\begin{array}{c}\text { Jogos Educativos para } \\
\text { crianças de 3-5: aprender } \\
\text { para a creche e pré-escola }\end{array}$ & Jogos & Escaleto UG & Português & Gratuito \\
\hline $\begin{array}{c}\text { Ativos! Livros para colorir } \\
\text { Vikings para crianças: } \\
\text { aprender a desenhar }\end{array}$ & Educação & Escaleto UG & Português & Gratuito \\
\hline $\begin{array}{c}\text { Colorific Lite - Livro de } \\
\text { desenhar e colorir }\end{array}$ & Jogos & $\begin{array}{c}\text { Alexey } \\
\text { Rashevskiy }\end{array}$ & Português & Gratuito \\
\hline
\end{tabular}



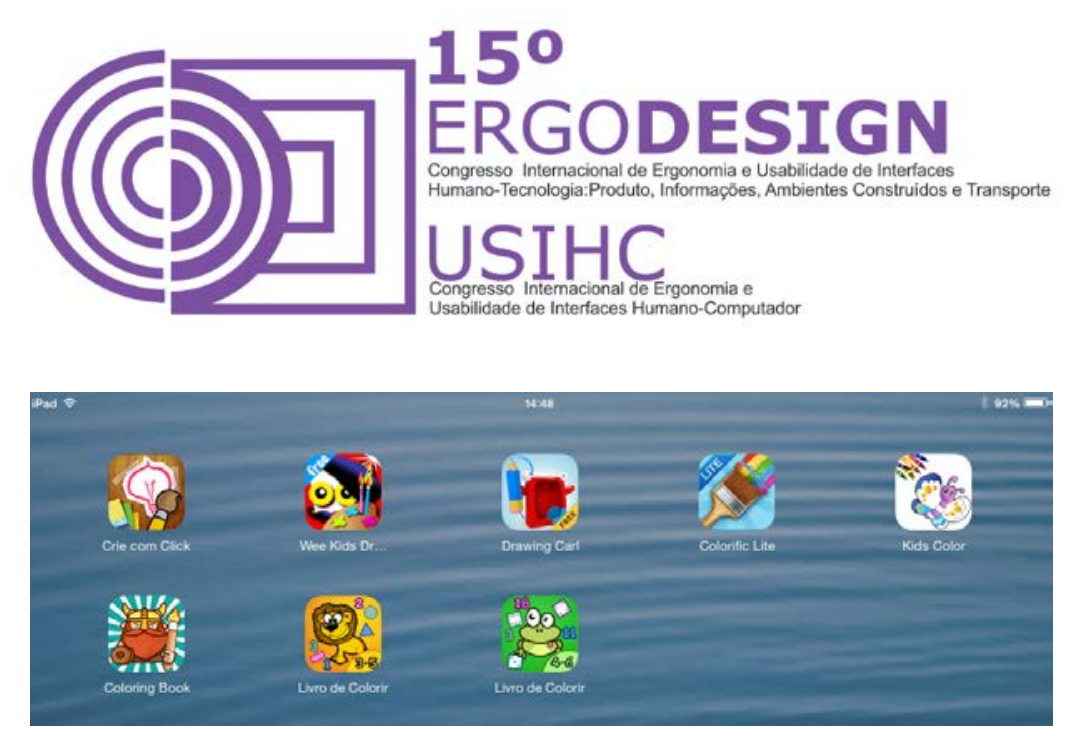

Figura 2 - Ícones dos aplicativos selecionados através da pesquisa na loja online.

\section{APLICATIVO SELECIONADO PARA TESTE}

O aplicativo selecionado para teste de reconhecimento de ícones foi o Livro de Colorir (Jogos Educativos para crianças de 3-5 anos: Aprender para a pré-escola). Desenvolvido pela empresa ESCALETO UG, disponibiliza grande número de aplicativos educacionais na Apple Store brasileira, detém mais de um milhão de downloads e se encaixa nas prerrogativas estabelecidas para a pesquisa. O aplicativo em questão apresenta ícones de difícil reconhecimento para o uso por crianças na faixa etária sugerida. Através do método de avaliação cooperativa, foi possível estabelecer parâmetros de reconhecimento dos ícones pelas crianças, para que a eficácia do aplicativo não fosse prejudicada.

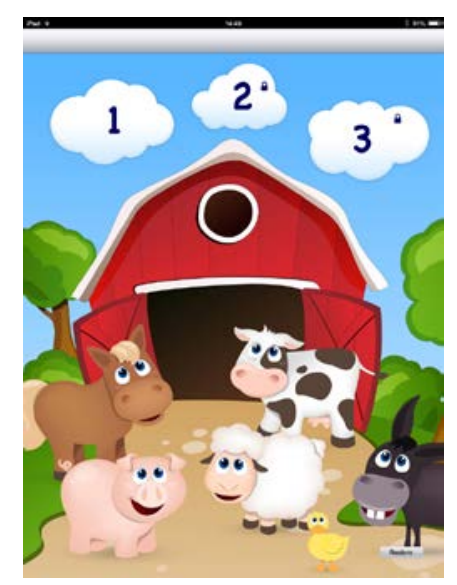

Figura 3 - Tela inicial. Não apresenta indicação das atividades propostas pelo aplicativo

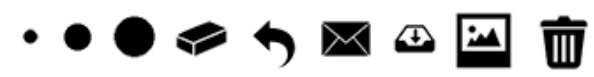

Figura 4 - Ícones da barra de ferramentas que apresentam problemas de reconhecimento pelas crianças. 

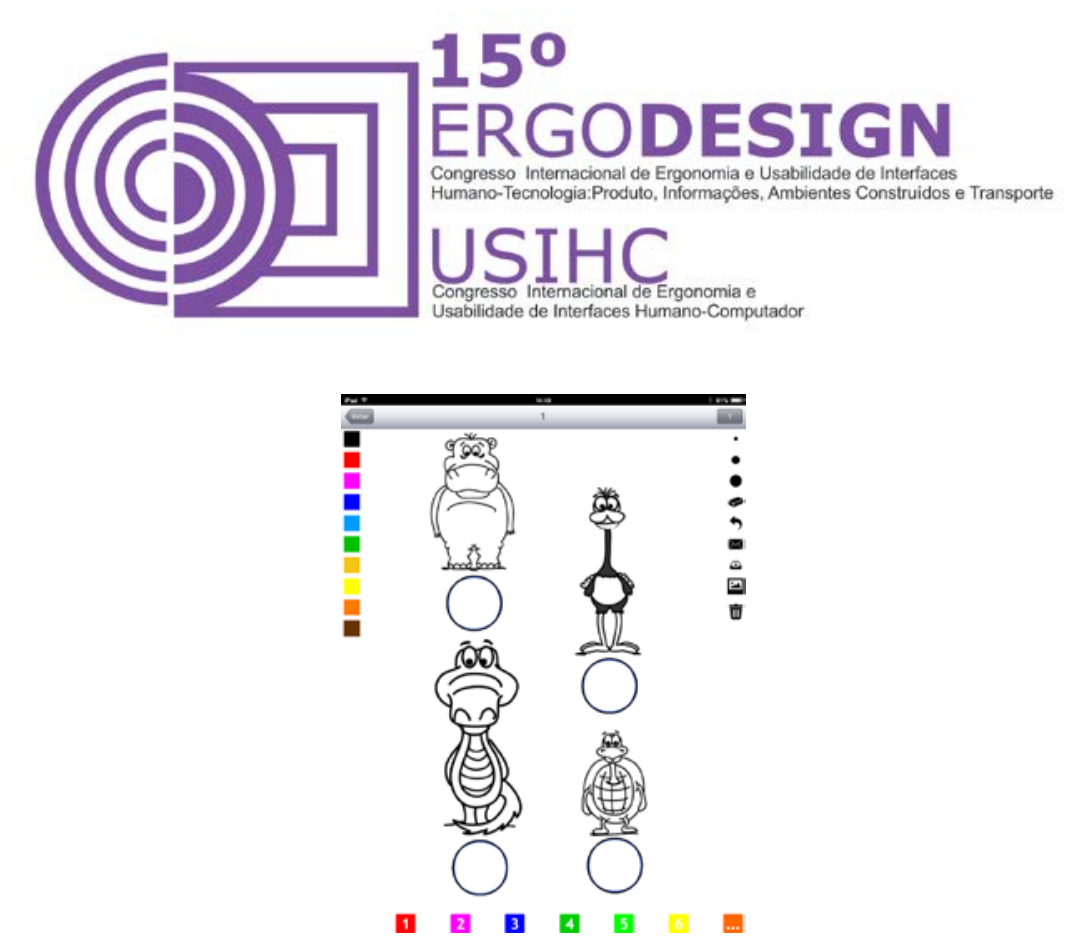

Figura 5 - Tela de atividades com os ícones que apresentam problemas de reconhecimento.

\section{PERFIL DOS USUÁRIOS E ESCOLHA DA AMOSTRA DE PARTICIPANTES (GRUPO DE USUÁRIOS)}

Para análise da eficácia dos ícones do aplicativo em questão, foram realizadas duas sessões de avaliação cooperativa com seis crianças cada, totalizando a amostragem de doze crianças, em uma escola particular no Rio de Janeiro. As crianças têm entre quatro e cinco anos, sendo seis meninos e seis meninas, todas com o perfil participativo e que apresentaram interesse no conteúdo do aplicativo. As doze crianças já haviam tido prévio contato com a tecnologia utilizada (tablets) e sabiam manipular o dispositivo sem problemas, sendo a interação através do toque realizada de forma intuitiva. Foi analisado o grau de reconhecimento e eficácia dos ícones utilizados na interface do aplicativo em questão.

\section{ATIVIDADES SELECIONADAS}

Foram elaboradas dez tarefas para serem realizadas com as crianças escolhidas para a atividade, de acordo com o perfil estabelecido. Essas atividades se relacionam com o manuseio do aplicativo, o uso e o reconhecimento dos ícones disponíveis. Através dessa análise, é possível identificar quais ícones fazem parte da linguagem da criança e de que forma elas os compreendem. As tarefas realizadas foram:

Tarefa 1 - Entrar no aplicativo. Ação esperada: a criança deve clicar no ícone do aplicativo para inicializá-lo. Após essa tarefa ela deve dar início às atividades propostas pelo aplicativo.

Tarefa 2 - Pintar os animais. Ação esperada: a criança deve clicar no ícone da paleta de cores para pintar o animal.

Tarefa 3 - Apagar a ação realizada. Ação esperada: clicar no ícone da borracha e apagar o que foi realizado.

Tarefa 4 - Alterar a espessura do pincel. Ação esperada: a criança deve tocar nos ícones dos círculos que alteram a espessura do pincel.

Tarefa 5 - Trocar de cor. Ação esperada: a criança deve escolher uma das cores disponíveis na paleta de cores, localizada à esquerda da tela.

Tarefa 6 - Desfazer ação (undo). Ação esperada: clicar no ícone da seta, localizado na barra de ferramentas, à direita da tela. 


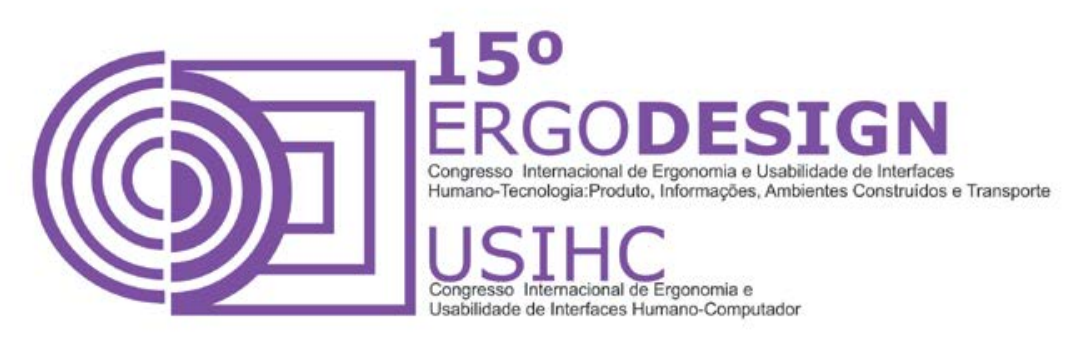

Tarefa 7 - Excluir desenho. Ação esperada: a criança deve clicar no ícone da lixeira e depois no botão YES.

Tarefa 8 - Salvar desenho. Ação esperada: clicar no ícone da caixa de entrada e depois no botão DESENHO ou DESENHO E FUNDO.

Tarefa 9 - Enviar desenho por e-mail. Ação esperada: clicar no ícone da carta e logo após no botão DESENHO ou DESENHO E FUNDO.

Tarefa 10 - Colocar um fundo (background). Ação esperada: clicar no ícone de fotos para inserir uma imagem previamente salva no dispositivo.

\section{RESULTADOS}

De acordo com a análise dos resultados, nenhuma das criancas que participaram da avaliação cooperativa conseguiu reconhecer todos os ícones e suas funções, o que prejudica o funcionamento e a eficiência do aplicativo no âmbito educacional, fazendo com que rapidamente abandonem a tarefa, por falta de interesse. Para que os aplicativos educacionais atinjam o seu objetivo eles precisam interagir de uma forma eficiente com as crianças.

De acordo com os testes realizados com base nas tarefas propostas, os resultados foram:

Tarefa 1 - todas as crianças conseguiram realizar a tarefa sem problemas. O acesso ao aplicativo se deu de forma imediata.

Tarefa 2 - para realizar esta tarefa, cinco crianças tentaram utilizar a paleta de cores que se encontra na parte inferior da tela. Essa paleta não é utilizada para pintar e sim para trocar de atividade. Percebeu-se um problema de localização da paleta de cores na interface.

Tarefa 3 - apenas uma criança utilizou a ferramenta da borracha pois já conhecia o aplicativo em teste. As demais não utilizaram a ferramenta em nenhum momento, pois não houve reconhecimento deste ícone. Em entrevista com a pedagoga responsável pela turma, foi informado que a borracha não faz parte do material escolar das crianças nessa faixa etária e portanto pode ter sido a causa do não reconhecimento do ícone da ferramenta.

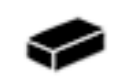

Figura 6 - Ícone da borracha.

Tarefa 4 - o ícone de alterar a espessura dos pincéis não foi percebido imediatamente por todas as crianças. Tão logo isso ocorreu, todos passaram a utilizá-lo sem maiores problemas.

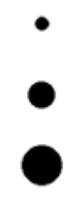

Figura 7 - Ícones para alterar a espessura do pincel.

Tarefa 5 - após a identificação da barra lateral, a tarefa passou a ser realizada sem maiores problemas. 


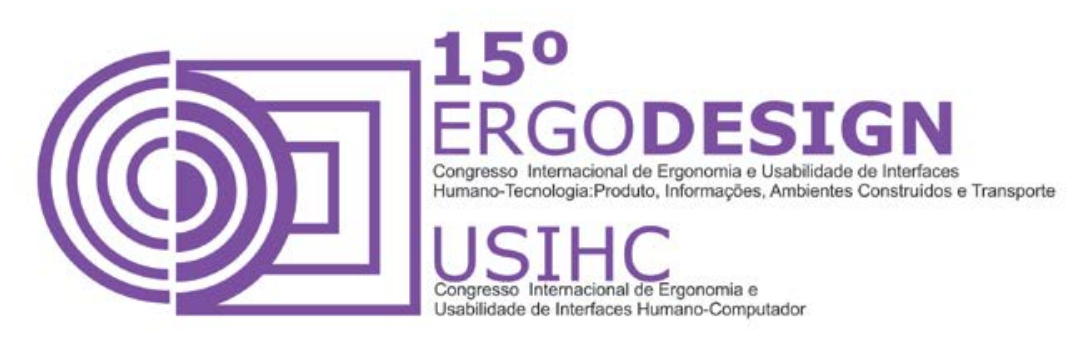

Tarefa 6 - nenhuma criança utilizou a ferramenta undo e nenhuma reconheceu este ícone como sendo uma ferramenta de desfazer uma ação realizada.

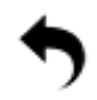

Figura 8 - Ícone "undo".

Tarefa 7 - ícone reconhecido de imediato. A ferramenta "deletar" foi utilizada amplamente, por onze crianças, mesmo em momentos onde a criança só desejava apagar parte do desenho. Como o reconhecimento da borracha e do undo não aconteceu com todas as crianças, elas recorreram ao ícone da lixeira para tal tarefa, o que acabava por apagar todo o desenho e não apenas parte dele. Outro problema apresentado foi o não reconhecimento do botão com a palavra "yes" (em inglês), para confirmação da tarefa, em conflito com o botão com a opção "não!" (em português), além da necessidade da leitura em uma faixa etária ainda não alfabetizada.

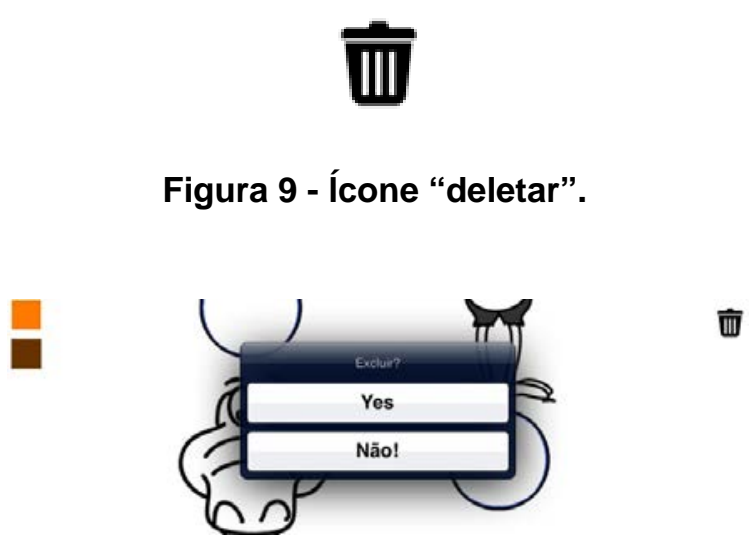

Figura 10 - Confirmação da tarefa excluir através de botões.

Tarefa 8 - nenhuma criança soube salvar o desenho. O ícone da caixa de entrada não foi reconhecido para esta tarefa. Segundo informação fornecida pela professora regente da turma com a qual a avaliação foi realizada, o comando "salvar" não é reconhecido pelas crianças dessa faixa etária, sendo alterado para "guardar". Mesmo com a troca semântica do termo, nenhuma criança que participou da avaliação soube realizar essa tarefa, pois não reconheceu o ícone proposto pelo aplicativo. Foi sugerido por uma delas, alterar o desenho para um cesto, pois é o local onde ela guarda seus brinquedos. Esta função também apresenta o problema de reconhecimento dos botões para confirmação da tarefa, sendo três opções de escolha: desenho, desenho e fundo e cancel. Como as crianças nessa faixa etária ainda não foram alfabetizadas, a execução correta da tarefa fica comprometida.

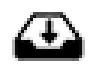

Figura 11 - Ícone "salvar". 

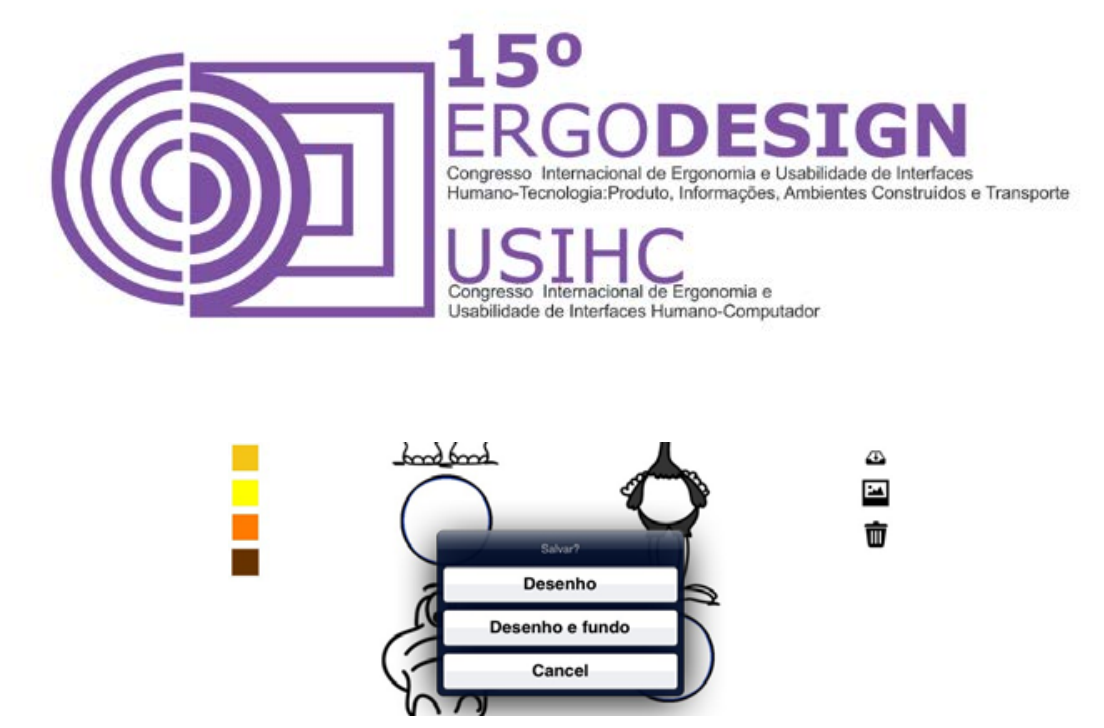

Figura 12 - Confirmação da tarefa salvar através de botões.

Tarefa 9 - ainda segundo informações da pedagoga, para as crianças dessa faixa etária a carta não faz parte de seu universo, já que estamos trabalhando com crianças da Geração Alfa, ou seja, nascidas em meio ao mundo digital, onde o envio de cartas pelo correio é cada vez mais escasso. Das seis crianças que participaram da avaliação, apenas duas reconheceram o ícone da carta como ferramenta de envio. Isso se deu devido ao conhecimento prévio da ferramenta de e-mail no ambiente familiar. Esta tarefa também exige a confirmação através dos botões desenho, desenho e fundo e cancel.

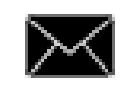

Figura 13 - Ícone "e-mail".

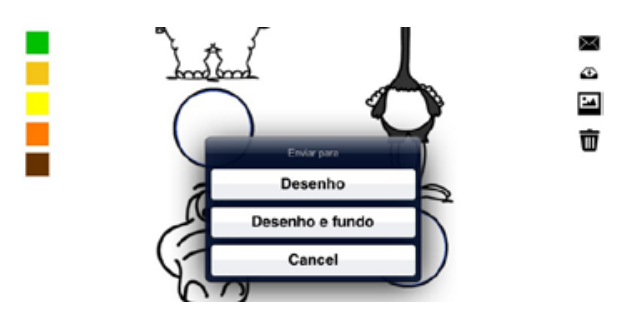

Figura 14 - Confirmação da tarefa enviar através de botões.

Tarefa 10 - nenhuma criança participante soube aplicar um fundo (background), tampouco se interessou em clicar no ícone proposto para esta tarefa, ficando a mesma inutilizada.

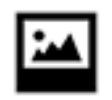

Figura 15 - Ícone "background". 

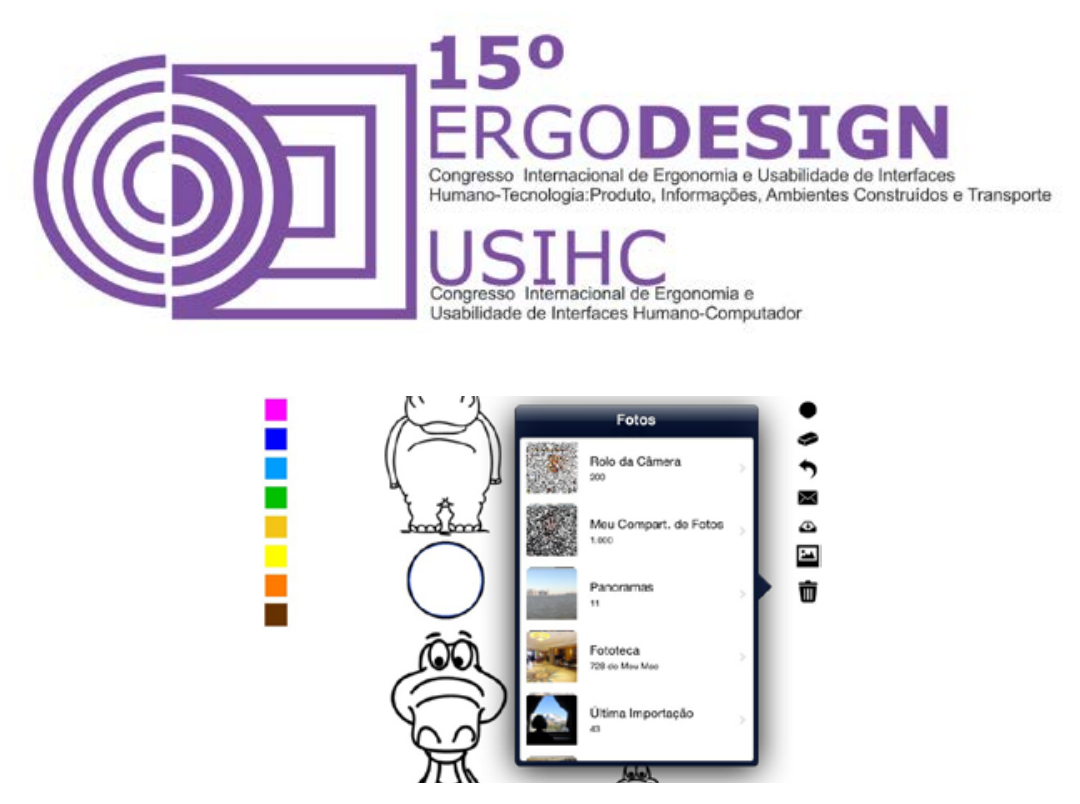

Figura 16 - Tarefa inserir fundo, realizada através do ícone "background".

\section{CONSIDERAÇÕES FINAIS}

A partir dos resultados da avaliação, percebe-se que os ícones utilizados não consideram o modelo mental dos alunos mas parecem ser simples adaptações e se adequam mais ao universo adulto do que ao infantil. Sugere-se ampliar a amostra, identificar outros aplicativos semelhantes e testá-los com mais de uma técnica. A fácil compreensão da navegação e dos ícones que compõem a interface precisam ser percebidas desde o início, fazendo com que as crianças mantenham o interesse pelo aplicativo e que estes contribuam para o aprendizado.

\section{REFERÊNCIAS BILBIOGRÁFICAS}

CHERUBIN, Karina Gomes. Para lidar com a geração Z, professores recorrem a redes sociais. Disponível em:<http://mpcidadania.ning.com/profiles/blogs/para-lidar-com-geracao-z-professorrecorre-as-redes-sociais>. Acesso em: 22 jul. 2014, 19:45:50.

CYBIS, Walter; BETIOL, Adriana Holtz; FAUST, Richard. Ergonomia e usabilidade: conhecimentos, métodos e aplicações. São Paulo: Novatec Editora, 2010.

LEE, V.; SCHNEIDER, H.; SCHELL, R. Aplicações móveis: Arquitetura, Projeto e Desenvolvimento. Rio de Janeiro: Editora Pearson, 2005.

MONK, A.; WRITGHT, P.; HABER, J.; DAVENPORT L. Imporving your human-computer interface: A practical technique. London: Prentice-Hall, 1993.

NIELSEN, Jakob; LORANGER, Hoa. Usabilidade na web: Projetando websites com qualidade. Rio de Janeiro: Elsevier, 2007.

OLIVEIRA, Sidnei. Geração Y - O Nascimento de uma nova Versão de Líderes. São Paulo: Integrare Editora, 2010.

SANTA ROSA, José Guilherme; MORAES, Anamaria de. Design Participativo. Técnicas de inclusão de usuários no processo ergodesign de interfaces. Rio de Janeiro: Rio Books, 2012.

SANTA ROSA, José Guilherme; MORAES, Anamaria de. Avaliação e projeto no design de interfaces. Teresópolis, RJ: 2AB, 2012.

SHINYASHIKI, Eduardo. Educação e as crianças da geração $Z$. Disponível em: $<$ http://www.administradores.com.br/informe-se/informativo/educacao-e-as-criancas-da-geracaoz/26948/>.Acesso em: 22 jul. 2014, 20:30:30. 